\title{
Protamine and Protamine-Insulins Exacerbate the Vascular Response to Injury
}

\author{
Elazer R. Edelman, * Laurel A. Pukac, ${ }^{\star}$ and Morris J. Karnovsky ${ }^{\star}$ \\ *Cardiovascular Division, Department of Internal Medicine, Brigham and Women's Hospital and Harvard Medical School, \\ Boston, Massachusetts 02115; Harvard-M.I.T. Division of Health Sciences and Technology, Massachusetts Institute of Technology, \\ Cambridge, Massachusetts 02139; and ${ }^{\ddagger}$ Department of Pathology, Harvard Medical School, Boston, Massachusetts 02115
}

\begin{abstract}
Endothelial cells and smooth muscle cells produce heparinlike compounds that are growth inhibitory for vascular smooth muscle cells, and it has been suggested that these compounds play a regulatory role that is perturbed with vascular injury. Indeed, exogenous heparin preparations effectively suppress smooth muscle cell proliferation following injury imposed on vascular endothelium. We now report that protamine, an agent that binds heparin and negates its anticoagulant properties, has potent stimulatory effects on vascular smooth muscle cell proliferation. The administration of protamine, alone or as part of commonly used insulin preparations, stimulated the proliferation of cultured smooth muscle cells, exacerbated vascular smooth muscle cell proliferative lesions in laboratory rats, and interfered with the growth-inhibitory effects of heparin in culture and in vivo. These results confirm the importance of endogenous heparinlike compounds in arterial homeostasis and may require reconsideration of protamine use following vascular reparative procedures and in diabetics. (J. Clin. Invest. 1993. 91:2308-2313.) Key words: arterial injury • endothelial cells • heparan sulfate $\bullet$ heparin $\bullet$ smooth muscle cells
\end{abstract}

\section{Introduction}

Endothelial cells ( 1 ) and smooth muscle cells (2) produce heparinlike compounds that are growth inhibitory for vascular smooth muscle cells, and it has been suggested that these compounds play a regulatory role that is perturbed with vascular injury (3). Smooth muscle cell proliferation following denuding vascular injury ceases upon reendothelialization, and substantial regression is noted $30 \mathrm{~d}$ after injury (4). Endothelial mitogens like acidic fibroblast growth factor (aFGF) selectively stimulate endothelial regeneration after denuding arterial in-

A portion of this work was presented in abstract form at the 1992 annual meeting of the American Heart Association in New Orleans, LA, and was awarded the Melvin A. Marcus Prize in Integrated Physiology.

Address reprint requests to Elazer R. Edelman, Department of Pathology, Harvard Medical School, D2-336, 200 Longwood Avenue, Boston, MA 02115.

Received for publication 16 November 1992 and in revised form 27 January 1993.

J. Clin. Invest.

(C) The American Society for Clinical Investigation, Inc.

$0021-9738 / 93 / 05 / 2308 / 06 \$ 2.00$

Volume 91, May 1993, 2308-2313 jury and minimize intimal hyperplasia from smooth muscle cells in areas where endothelium was made intact (5). Conditioned media from confluent cultures of endothelial cells inhibit vascular smooth muscle cell growth. In major part this effect seems to be the result of a heparinlike compound, as exposure of the media to heparinase abolishes smooth muscle cell growth inhibition (1). Exogenous preparations of heparin $(10-100 \mu \mathrm{g} / \mathrm{ml})$ inhibit DNA synthesis in growth arrested cells released from $\mathrm{G}_{0}$ block ( 3 ), and continuous infusion of heparin from osmotic pumps almost completely abolishes intimal smooth muscle cell proliferation in denuded arteries (4). We have previously demonstrated that the local perivascular administration of these compounds achieves the same effect, and for some compounds is the only effective means of suppressing smooth muscle cell proliferation (6). Perivascular administration is achieved by placing matrix type polymeric controlled delivery devices adjacent to arteries of interest. The drug is released from these devices into the perivascular space with predictable and repeatable kinetics and is then absorbed and distributed throughout the wall of the artery. This provides for heightened local concentrations at relatively low doses of drug released and without systemic dosing or side effects. When heparin is administered in this fashion, the expected smooth-muscle-cell proliferation following arterial injury is suppressed to a greater extent than intravenous heparin delivery, without systemic anticoagulation (6). Perivascular administration probably increases local drug concentrations but may also act on specific adventitial receptors. The potency of perivascular administration lends further support to a model of regional control of vascular homeostasis that involves heparan sulfate and similar compounds. Local release of heparinlike compounds maintains smooth muscle cells quiescent in the face of the constant barrage of minor insults that strike the vessel surface, but when injury to endothelial cells is overwhelming this check is removed in part or entirety.

To further investigate this model of the vascular injury we sought to neutralize endogenously secreted and exogenously administered heparin with protamine. The protamines are a family of basic proteins rich in arginine, purified from fish sperm (7) and used in a diverse set of medical circumstances. Protamine neutralizes the anticoagulant properties of heparin by establishing a 1:1 pairing of cationic sites with anionic heparin sites $(8,9)$. As a result protamine infusions are used to reverse systemic anticoagulation following most cardiac catheterization and cardiovascular surgical operations (10). In addition, protamine serves as the crucial element in producing clinically potent, long-acting insulins. The activity of protamine zinc insulin peaks $18-36 \mathrm{~h}$ after subcutaneous injection because it contains $0.3 \mathrm{mg}$ protamine per $\mathrm{mg}$ insulin. Similarly 
neutral protamine Hagedorn (NPH) insulin activity peaks at $8-12 \mathrm{~h}$ because of the presence of $0.125 \mathrm{mg}$ protamine per $\mathrm{mg}$ of insulin. That protamine is absorbed and metabolized by the body can be inferred from the presence of $\mathrm{IgG}$ antibodies to protamine in $93 \%$ of patients treated with NPH insulin and $90 \%$ of those treated with protamine zinc insulin $(\mathrm{PZI})^{1}(11)$. In fact, $99.7 \%$ of all reactions to protamine occur in protamine-insulin-dependent diabetics (12).

We therefore administered clinically relevant doses of protamine to laboratory rats in the setting of arterial injury to determine if therapeutically administered protamine might effect vascular repair. In the first case protamine was injected at the conclusion of experimental arterial injury. This resembles the use of protamine as a heparin reversing agent. In the second case animals received continuous release or repeated subcutaneous injections of protamine alone or as part of an insulinprotamine complex in a manner akin to the protamine exposure of insulin-dependent diabetics.

\section{Methods}

Intimal hyperplasia and smooth-muscle-cell proliferation. Endothelial denudation of the left common carotid artery in 300-500-g male Sprague-Dawley rats (Charles River Breeding Laboratories, Kingston, MA) was performed with a 2 French fogarty balloon catheter (American Edwards Laboratories, Santa Ana, CA) (13). Rats were anesthetized with intraperitoneal sodium Nembutal $0.05 \mathrm{mg} / \mathrm{g}$ body wt. A midline incision exposed the distal left common and external carotid arteries. The balloon catheter was introduced into the external carotid artery and passed three times with the balloon distended sufficiently with air to generate slight resistance. Upon removal of the catheter the external carotid artery was ligated. The contralateral artery underwent identical manipulation save for the introduction of the balloon catheter.

Protamine administration. To see if the means by which protamine is typically used in the therapeutic realm could have an effect on vascular repair we administered protamine immediately following arterial injury both as a single bolus injection and in a continuously releasing fashion from a subcutaneous depot. In the first set of experiments 30 animals were subjected to balloon injury: 8 received a single injection of heparin (heparin 1453, 12,000-18,000 D, U.S.P. $160 \mathrm{U} / \mathrm{mg}$, Institute de Choay, Paris, France; $437.5 \mu \mathrm{g} / \mathrm{kg}$ ) immediately prior to the procedure and an injection of protamine sulfate $(\sim 5000 \mathrm{D}, 1.3 \mathrm{mg} /$ $\mathrm{kg}$; Sigma Immunochemicals, St. Louis, MO) immediately afterward; 8 received heparin alone; 8 protamine alone; and 6 animals served as controls without any additional pharmacologic therapy.

In a separate set of experiments protamine was administered from subcutaneously implanted polymer-based controlled release devices $(6,14)$. Dry powdered drug was added to a solution of ethylene-vinyl acetate copolymer (EVAc; DuPont Co., Wilmington, DE) dissolved in dichloromethane $(10 \% \mathrm{wt} / \mathrm{vol})$ to achieve a final ratio of $33 \% \mathrm{wt} / \mathrm{wt}$. The drug-polymer suspension was poured into precooled glass molds, removed after hardening, and placed at $-20^{\circ} \mathrm{C}$ and then under vacuum (600 mTorr) for $2 \mathrm{~d}$ each. The resultant matrix was a homogeneous dispersion of drug within a porous network of EVAc (14). Smaller pellets were cut from the larger slabs and coated with four layers of EVAc. Drug release was restrained to emanate from a hole in the coating and near zero-order kinetics obtained in this fashion $(6,15)$. Three different-sized matrices were made so as to deliver the polycation with identical kinetics at $32.7,176.6$, or $820.9 \mu \mathrm{g} / \mathrm{kg}$ rat per day over the 3-wk duration of the experiments. The three types of EVAc:protamine

1. Abbreviations used in this paper: BrdU, 5-bromo-2'-deoxyuridine; CZI, crystalline zinc insulin; EVAc, ethylene-vinyl acetate co-polymer; PCNA, proliferating cell nuclear antigen; PZI, protamine zinc insulin. matrices were inserted in the abdominal subcutaneous space of 54 rats; 18 rats per group. After a week of pretreatment animals were subjected to routine balloon induced denuding injury. Half of the animals in a group received no further therapy, and in the other animals, heparincontaining matrices were placed alongside the injured artery. This means of local heparin administration has proven to be especially effective in reducing intimal hyperplasia following denuding vascular injury (6). A separate group of 12 animals served as controls; 6 were subjected to balloon injury alone and 6 to balloon injury with perivascular heparin release. Finally, 6 other animals had an intermediate size protamine releasing polymer matrix ( $209.5 \mu \mathrm{g} / \mathrm{kg}$ per d) placed in the perivascular region of the injured common carotid artery to determine whether local protamine delivery might provide heightened local concentrations of protamine and an increased effect. When a protamine matrix was already alongside the artery a second matrix releasing heparin could not be added, as the relative size of the two matrices precluded this in practice and the possibility that the heparin and protamine might bind together before reaching the artery served as a theoretical contraindication.

Protamine-insulin. The vascular effects of protamine containing insulins was studied in rats made diabetic with the tail-vein injection of $65 \mu \mathrm{g} / \mathrm{kg}$ streptozotocin (UpJohn Co., Inc., Kalamazoo, MI). The diabetic state was confirmed with serial determinations of blood and urine glucose during a 7-d observation period. 15 animals were then begun on twice-daily injections of crystalline zinc insulin (CZI, U-100; Eli Lilly \& Co., Indianapolis, IN), and 16 animals on single injections of protamine zinc insulin (PZI, U-100; Eli Lilly \& Co.). Insulin dosing was guided by daily determinations of blood and urine glucose. Blood glucose was maintained at $80-120 \mathrm{mg} / \mathrm{dl}$, and urinary glucose at 0 , such that typical doses for crystalline zinc insulin included $40 \mathrm{U} / \mathrm{kg}$ per $\mathrm{d}$ and protamine zinc insulin $20 \mathrm{U} / \mathrm{kg}$ per $\mathrm{d}$. After $1 \mathrm{wk}$ of satisfying these conditions animals were subjected to denuding balloon injury of their left common carotid artery.

Tissue processing. On the 14th postoperative day animals were euthanized and perfused clear retrograde via the abdominal aorta with lactated ringers followed by fixation with modified Ito-Karnovsky's ( $4 \%$ paraformaldehyde, $0.05 \%$ glutaraldehyde, and $15 \%$ saturated picric acid in $0.1 \mathrm{M}$ sodium phosphate buffer, $\mathrm{pH} 7.4$ ) or Carnoy's fixative (60\% methanol, 30\% chloroform, 10\% glacial acetic acid). The location of the implanted devices was noted and the devices recovered with the intact arteries. Both common carotid arteries were harvested and cut into three equal segments. The segments were paraffin embedded and microtome sectioned. 8-12 sections along the length of each segment were obtained and stained with hematoxylin/eosin or verHoeff's elastin stain. The intimal, medial, and adventitial areas, the intima/ media area ratio, and the percent of luminal occlusion were calculated for each arterial segment using computerized digital planimetry with a dedicated video microscope and individualized software. The averages of all sections and segments were used for comparison. Edge detection software was further used to detect cell number within 8-32 sections per media or intima and, when combined with area data, used to determine cell density. All analyses were confirmed by visual inspection, and the accuracy of the system verified with a series of matched manual cell density determinations.

Immunocytochemistry. Sections were also stained with antibodies to proliferating cell nuclear antigen (PCNA) to delineate proliferating cells and to smooth muscle cell actin to identify smooth muscle cells. In experiments with the diabetic animals, cell proliferation was also followed over the entire duration of the experiment by injecting the thymidine analogue 5-bromo-2'-deoxyuridine (BrdU; New England Nuclear, Boston, MA; DuPont Corp., Wilmington, DE) at $50 \mathrm{mg} / \mathrm{kg}$ i.p., every 4 to $7 \mathrm{~d}$, from the 3rd d after injury and $1 \mathrm{~h}$ before being killed. Intracellular BrdU was identified immunocytochemically. This enabled us to match the PCNA determination of cell proliferation with the BrdU assay of DNA synthesis, and to examine whether heparin and/or protamine effected the expression of PCNA.

Immunocytochemical analyses was performed as follows. Arterial sections were deparaffinized in xylene and ethanol baths. Endogenous 
peroxidase activity was quenched with a 20 -min immersion in a solution of $200 \mathrm{ml}$ methanol with $50 \mathrm{ml}$ of $3 \%$ hydrogen peroxide. Nonspecific antibody binding was prevented by preincubating the tissues for 20 min with serum (1:10) from species other than those used to raise the primary antibody. The sections were then exposed to the primary antibody (Coulter Immunology, Hialeah, FL) to PCNA (60 min), BrdU (60 min) and smooth muscle cells ( $90 \mathrm{~min}$ ). Mouse IgG antiPCNA was diluted 1:2,000, mouse anti-BrdU 1:50 and mouse antismooth muscle cell actin was used at 1:5,000. After the sections were rinsed in PBS, they were incubated for an additional hour with biotinylated IgG directed against the secondary antibody. Peroxidase labeling was achieved with a $1-\mathrm{h}$ incubation using avidin/peroxidase complex (Vector Labs, Inc., Burlingame, CA). Antibody visualization was established after a 5-min exposure to $0.05 \%$ 3,3'-diaminobenzidine (Sigma Chemical Co., St. Louis, $\mathrm{MO}$ ) in $0.05 \mathrm{M}$ Tris- $\mathrm{HCl}$ at $\mathrm{pH} 7.6$ with $0.003 \%$ hydrogen peroxide. In other sections antibody visualization was obtained with alkaline phosphatase. After incorporation of the secondary antibody was complete, slides were rinsed and soaked in PBS, incubated for $1 \mathrm{~h}$ with $\mathrm{ABC}$-alkaline phosphatase solution, rinsed again with $\mathrm{PBS}$, and exposed to $\mathrm{ABC}$-alkaline phosphatase substrate diluted in $5 \mathrm{ml}$ of Tris- $\mathrm{HCl}$ at $\mathrm{pH} 8.2$ for $10-30 \mathrm{~min}$. Sections were counterstained with methyl green or hematoxylin.

Effects on smooth muscle cells in culture. The effects of protamine on smooth muscle cell proliferation were measured on smooth muscle cells cultured from Sprague-Dawley rat aortas (passage 6-10). Cells were growth arrested in culture for $48 \mathrm{~h}$ in $0.4 \% \mathrm{FCS} / \mathrm{RPMI}$ medium and then released from $\mathrm{G}_{0}$ by addition of $20 \%$ FCS/RPMI with increasing doses of protamine, with or without $10 \mu \mathrm{g} / \mathrm{ml}$ of heparin. After $4 \mathrm{~d}$ the smooth muscle cells were washed in $\mathrm{Ca}^{++}$and $\mathrm{Mg}^{++}$-free Hanks' Hepes and released from the dish by trypsinization. Cell number was determined using a Coulter counter. Each data point is presented as the mean \pm SE for three separate experiments performed with triplicate wells at each dose. Percent inhibition or stimulation of proliferation was measured as:

$100 *\left[\frac{\text { cell number in } 20 \% \text { FCS plus heparin and/or protamine }}{\text { cell number in } 20 \% \text { FCS }}-1\right]$.

Thus, a positive value indicates stimulation of proliferation above that provided by $20 \%$ FCS, and a negative number indicates inhibition of the stimulation provided by $20 \%$ FCS.

Statistics. Data are presented as the mean \pm SE. Statistical comparisons were performed with nonpaired $t$ test for groups of unequal sample sizes, paired $t$ test for coupled data, chi-square analysis or ANOVA when appropriate. Data were rejected as not significantly different if $P$ values of greater than 0.05 were observed. Data line fits were established using a linear regression model.

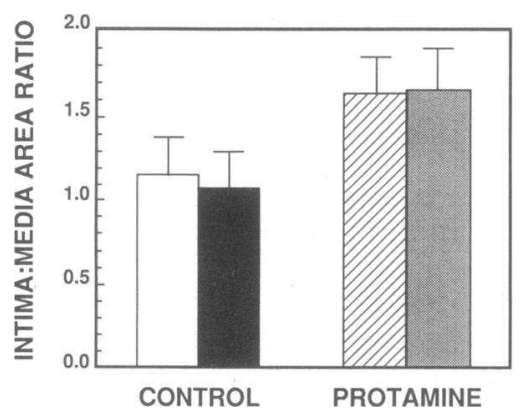

Figure 1. A single intravenous injection of protamine sulfate stimulates intimal hyperplasia. Animals were treated with a single intravenous injection of protamine (cross-hatched bar, $1.3 \mathrm{mg} / \mathrm{kg}$ ) immediately after denuding arterial injury and/or heparin (stippled bar, $437.5 \mu \mathrm{g} / \mathrm{kg}$ ) immedi-

ately before injury. Protamine increased the amount of intimal hyperplasia observed $2 \mathrm{w}$ after endothelial denudation whether heparin was administered ( stippled bar, $40.5 \%$ increase, $P<0.03$, compared with control, dark bar) or not (cross-hatched bars, $50 \%$ increase, $P$ $<0.04$ compared with control, clear bar). The single injection of heparin (dark bar) had no effect $(P=\mathrm{NS})$.

\section{Results}

Neointimal hyperplasia: protamine and/or heparin. When we administered protamine sulfate as a single intravenous bolus injection, at a dose typically used to reverse systemic heparinization following cardiac catheterization or cardio-pulmonary bypass $(1.3 \mathrm{mg} / \mathrm{kg})$, with or without heparin $(437.5 \mu \mathrm{g} / \mathrm{kg})$,
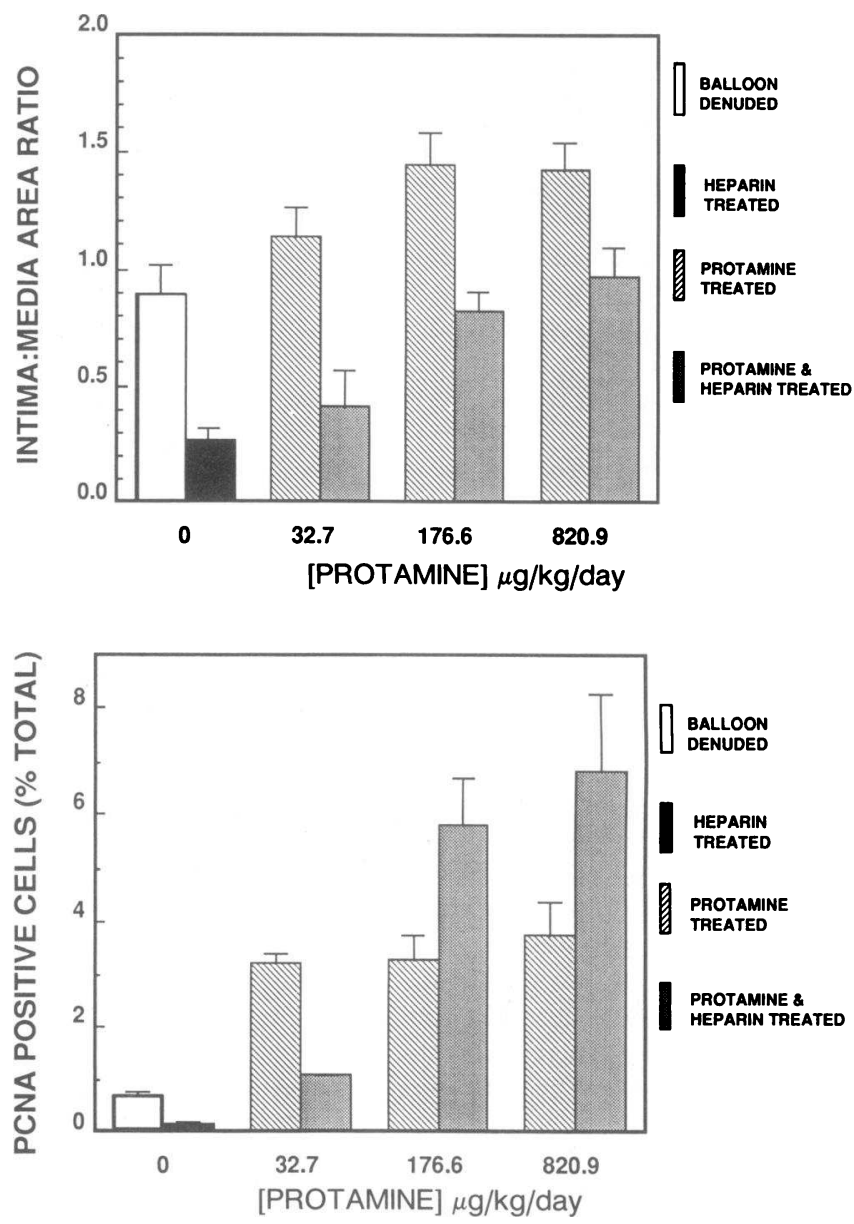

Figure 2. $(A)$ Continuous release of protamine sulfate stimulates intimal hyperplasia and prevents the growth-inhibitory effects of heparin. Solvent cast ethylene-vinyl-acetate copolymer drug matrices continuously released protamine into the abdominal subcutaneous space at three different doses and heparin into the perivascular space of balloon-denuded carotid arteries at $183.3 \mu \mathrm{g} / \mathrm{kg}$ per $\mathrm{d}$. The controlled release of heparin reduced intimal hyperplasia $2 \mathrm{w}$ after arterial injury $71.0 \%$ (dark vs. clear bars, $P<0.0001$ ). Intimal hyperplasia rose when protamine was released from the matrices for $7 \mathrm{~d}$ before the arterial injury and carried out for an additional 2 wk (8-10 rats per dose) above the control rats (hatched bars), and negated the antiproliferative effect of simultaneous perivascular heparin release (stippled bars, $P<0.0001$ compared with respective controls) in a dose-dependent fashion. $(B)$ Continuous release of protamine sulfate stimulates cell proliferation and prevents the growth-inhibitory effects of heparin. The effect of protamine on intimal hyperplasia was mirrored by an increase in intimal cell proliferation as determined by immunoperoxidase identification of the presence of PCNA. Cell proliferation was increased more than 4-fold above control for all doses of protamine studied ( hatched bars). Heparin alone reduced cell proliferation $78 \%$ (dark vs. clear bars, $P<0.001$ ) and increasing doses of protamine reversed this antiproliferative effect (stippled bars) such that, at the two higher protamine doses, growth stimulation predominated and even exceeded the effects of protamine alone. 
intimal hyperplasia was increased $46.7 \pm 6.1 \%(P<0.04$ compared with control, Fig. 1). In contrast, a single intravenous bolus of heparin had no effect on intimal area.

To examine the effects of repeated exposure to protamine such as might occur with multiple daily injections of protamine-containing insulins, we released protamine from subcutaneously implanted polymer/drug matrices for $1 \mathrm{wk}$ before and $2 \mathrm{wk}$ after arterial injury. Protamine-treated animals exhibited greater intimal hyperplasia ( Fig. $2 A$ ), and more cell proliferation (Fig. $2 B$ ) than untreated controls at all doses. At 820.9 $\mu \mathrm{g} / \mathrm{kg}$ per $\mathrm{d}$ of protamine, intimal extracellular area was increased $30.4 \pm 4 \%$ above controls. In the absence of protamine, heparin released from a controlled release device in the perivascular space reduced intimal hyperplasia in comparison to untreated control rats by $71 \%$ (Fig. $2 \mathrm{~A}$ ). Increasing doses of protamine progressively negated heparin's inhibition of intimal growth (Fig. $2 A$ ) and cell proliferation (Fig. $2 B$ ), such that the highest dose of protamine examined completely reversed the inhibitory effects of heparin and produced intimal hyperplasia exceeding that seen in control animals by $8.8 \%$.

Similar results were obtained with cultured rat vascular smooth muscle cells. Protamine altered the mitogenic response of aortic smooth muscle cells isolated from the same species of rat used in the in vivo experiments. Protamine increased the growth of vascular smooth muscle cells above growth in $20 \%$ FCS alone in a dose-dependent manner. The expected inhibition of growth in FCS by heparin was negated by protamine (Fig. 3). Thus, increasing doses of protamine provided progressively more growth stimulation and reduced the growth-inhibitory effects of heparin.

Protamine-insulin. To determine whether the same effects observed with protamine alone might be observed with protamine containing insulins, we investigated the differential vascular effects of protamine-containing and protamine-free insulins in streptozotocin-induced diabetic rats. Neointimal hyperplasia following balloon arterial injury was markedly reduced in streptozotocin-diabetic animals compared with control animals (Fig. 4). These results mirror classic studies documenting a reduction in hypercholesterolemic diet-induced atherosclerotic lesions in diabetic animals and the negation of this protection by subsequent administration of insulin (16-20).

We now demonstrate the differential effects of protaminecontaining and protamine-free insulins on intimal hyperplasia. Injections of PZI ( $0.3 \mathrm{mg}$ protamine $/ \mathrm{mg}$ insulin $)$ increased

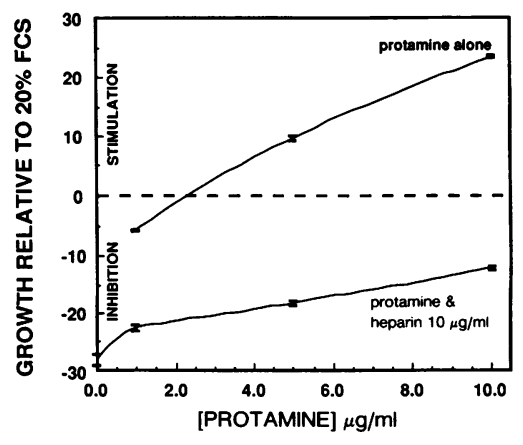

Figure 3. Protamine stimulated growth of cultured vascular smooth muscle cells and negated heparin inhibition of their growth. Growth-arrested, cultured Sprague-Dawleyrat aortic smooth muscle cells were stimulated by the addition of $20 \%$ FCS; 20\% FCS plus protamine $(1,5,10 \mu \mathrm{g} /$ $\mathrm{ml})$; or $20 \%$ FCS, prot-

amine and heparin $(10 \mu \mathrm{g} / \mathrm{ml})$. Cell number was determined after 4 d. The highest dose of protamine stimulated growth $23.4 \pm 0.3 \%$ above $20 \%$ FCS alone and reduced the growth-inhibitory effects of heparin by $56.4 \%$.

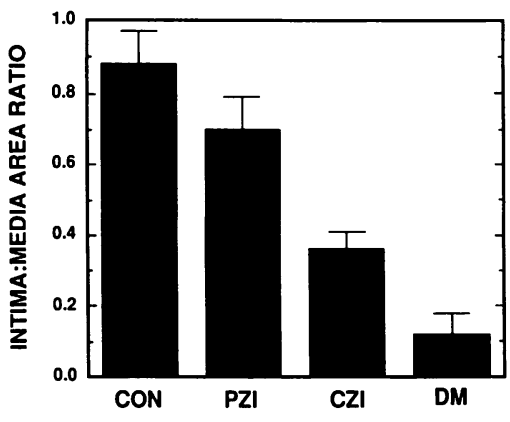

Figure 4. Protamine containing insulin restores glucose control in diabetic animals but exacerbates vascular injury. Sprague-Dawley rats were made diabetic with tail vein injections of streptozotocin $(65$ $\mathrm{mg} / \mathrm{kg}$ ). Diabetic animals (DM, $n=6$ ) were maintained with no additional therapy, and other rats were injected with protamine containing insulin (PZI, $n=$ 12 ) or nonprotamine insulin (CZI, $n=12$ ). Intimal hyperplasia 2 $\mathrm{w}$ after arterial injury was substantially lower in diabetic animals than controls ( $\mathrm{DM}$ vs. CON, $P<0.005$ ) and insulin therapy negated this protective effect. Protamine containing insulin (PZI, $n=12$ ) increased lesion area 5.2-fold above that seen in the untreated diabetic animals $(P<0.04)$, while the area of the neointima in animals treated with injections of nonprotamine insulin (CZI, $n=12$ ) was increased to a far lesser, and not statistically significant, degree than the area observed in the diabetics.

intimal hyperplasia 5.2-fold above that observed in untreated diabetic rats $(P<0.005$, Fig. 4$)$, such that the values were statistically indistinguishable from those obtained in the nondiabetic control animals. The increase in intimal area with protamine-free crystalline zinc insulin CZI injections was substantially lower than that seen with protamine-insulin-treated animals $(P<0.04$, Fig. 4$)$. Changes in cell proliferation (Table I) and intimal hyperplasia were not related to differences in regulation of glucose or lipid metabolism. Though diabetic rats were hyperglycemic $(400-500 \mathrm{mg} / \mathrm{dl})$ and hypercholesterolemic ( $P<0.03$ compared with controls), serum glucose, cholesterol, and $\mathrm{HbA}_{1} \mathrm{c}$ values in the crystalline zinc insulin and protamine zinc insulin treated rats were indistinguishable and not statistically different from those of nondiabetic controls (Table I).

Table I. Effects of Diabetes and Insulin Injections on Indices of Intimal Cell Proliferation, Glycosylated Hemoglobin Levels and Serum Cholesterol

\begin{tabular}{lccc}
\hline & $\begin{array}{c}\text { Proliferating } \\
\text { cells }\end{array}$ & $\mathrm{HbA}_{1} \mathrm{c}$ & Cholesterol \\
\hline & $\%$ total & $\%$ & $\mathrm{mg} / \mathrm{dl}$ \\
& & & \\
Untreated diabetics & $25.93 \pm 2.9$ & $6.94 \pm 1.34$ & $72.0 \pm 5.5$ \\
PZI treated diabetics & $26.04 \pm 2.1$ & $2.38 \pm 0.08$ & $54.0 \pm 3.1$ \\
CZI treated diabetics & $20.42 \pm 2.1$ & $2.46 \pm 0.28$ & $52.3 \pm 2.4$ \\
Nondiabetic & $21.90 \pm 0.5$ & $2.15 \pm 0.06$ & $56.0 \pm 4.6$
\end{tabular}

Cell proliferation was determined immunocytochemically by intracellular incorporation of the thymidine analogue 5-bromo- $2^{\prime}$-deoxyuridine injected at $50 \mathrm{mg} / \mathrm{kg} \mathrm{3,7}$, and $14 \mathrm{~d}$ after injury. PZItreated animals had increased cell proliferation in comparison to control or CZI-treated animals ( $t$ test, $P<0.04$ ), but glycosylated hemoglobin $\left(\mathrm{HbA}_{1} \mathrm{c}\right)$ and serum cholesterol levels for either of the treated animal groups were not statistically different from those of nondiabetic controls. In contrast diabetic rats were relatively hypercholesterolemic $\left(P<0.03\right.$ compared with controls) and their $\mathrm{HbA}_{1} \mathrm{c}$ was increased threefold, reflecting persistently elevated blood glucose levels at $400-500 \mathrm{mg} / \mathrm{dl}$. 


\section{Discussion}

The administration of protamine, alone or as part of commonly used insulin preparations, stimulated the proliferation of cultured smooth muscle cells, exacerbated vascular smooth muscle cell proliferative lesions in laboratory rats, and interfered with the growth-inhibitory effects of heparin in culture and in vivo.

Heparin, protamine and the vascular response to injury. Heparan-mediated control of vascular repair has been proposed as an important regulator of vascular injury. Endothelial cells (1), and perhaps smooth muscle cells (2), produce or moderate the production or release of heparinlike compounds that inhibit DNA synthesis and subsequent growth of smooth muscle cells (3). Exogenous heparin is especially effective in suppressing the intimal hyperplastic lesion that results from smooth muscle cell proliferation following vascular injury (4), and the regression of smooth muscle cell proliferation following reendothelialization may be mediated by the release of heparinlike compounds. Aside from suppressing smooth muscle cell migration and proliferation (1-4), heparin also alters the form and extent of extracellular matrix elaboration (21-23), the activity of heparanase $(24,25)$, and the stability and activity of specific growth factors $(26,27)$.

The protamines are a family of basic proteins rich in arginine (7), which ionically bind heparin and inactivate heparin's anticoagulant activity $(9,28-31)$. We now demonstrate that protamine can negate the vascular antiproliferative effects of heparin as well as the antithrombotic effects. Heparin's ability to inhibit smooth muscle cell proliferation is distinct from its anticoagulant effects, as chemically modified heparin whose anticoagulant activity had been removed proved to be just as potent on a mass basis at inhibiting smooth-muscle-cell proliferation $(6,32,33)$. Thus, protamine may interrupt vascular repair by binding heparin or endogenous heparinlike compounds, or by some direct mechanism of its own. For example, protamine may interfere with the ability of heparan sulfate proteoglycan to bind and sequester growth factors or to block soluble heparinlike compounds from preventing heparin-avid growth factors from binding to their receptors. Indeed, protamine has been demonstrated to affect binding and mitogenicity of the heparin avid-growth factors, PDGF (34-36), and both acidic and basic fibroblast growth factor (37). Protamine has also been reported to inhibit angiogenesis and in that regard was proposed as a putative antineoplastic agent $(38,39)$.

The data we now present lends further support to the complexity of vascular repair and the importance of heparinlike compounds in mediating vascular injury. That indices of proliferation are increased (Fig. $2 B$ and Table I) but exhibit a nonlinear relationship with the concomitant rise in intimal hyperplasia (Fig. $2 \mathrm{~A}$ ) in all likelihood reflects the complexity of the generation and propagation of the neointimal lesion that involves migration of smooth muscle cells and elaboration of extracellular matrix as well as cell proliferation. The potent effects of a single dose of protamine, in contrast to the lack of a discernible effect on intimal hyperplasia from a single injection of heparin, further highlight the wide range of effects that might result from protamine.

Clinical implications. There is already significant concern with the continued use of protamine for reversal of systemic heparinization (40-43). Protamine reactions include hypoten- sion and vascular collapse (12), as well as effects on hematologic and pulmonary function $(40,41,43,44)$. Our study might add the potential for exacerbation of proliferative vascular disease to this list. In the setting of vascular injury and vascular manipulation, such as arterial bypass or angioplasty, protamine administration may be especially harmful. Vasculoproliferative complications may be especially problematic for protamine-insulin dependent diabetics and/or patients receiving protamine for heparin reversal following arterial bypass or angioplasty. Both of these patient groups are already at increased risk of developing accelerated arteriopathies that limit the utility of angioplasty and bypass surgery $(45,46)$. Further animal and human trials might better determine the strength of these associations and may change the way we treat both diabetes and atherosclerosis.

\section{Acknowledgments}

We thank Amy Newton for technical assistance.

This work was supported by grants from the National Institutes of Health HL 17747 (M. J. Karnovsky), and a Physician-Scientist Award of the National Institutes of Health, K12 AG00294 (E. R. Edelman).

\section{References}

1. Castellot, J. J., Jr., M. L. Addonizio, R. Rosenberg, and M. J. Karnovsky. 1981. Cultured endothelial cells produce a heparinlike inhibitor of smooth muscle cell growth. J. Cell Biol. 90:372-9.

2. Fritze, L. M. S., C. F. Reilly, and R. Rosenberg. 1985. An antiproliferative heparan sulfate species produced by postconfluent smooth muscle cells. J. Cell. Biol. 100:1041-1049.

3. Castellot, J. J., Jr., D. L. Cochran, and M. J. Karnovsky. 1985. Effect of heparin on vascular smooth muscle cells. I. Cell metabolism. J. Cell Physiol. 124:21-28.

4. Clowes, A. W., and M. J. Karnovsky. 1977. Suppression by heparin of smooth muscle cell proliferation in injured arteries. Nature (Lond.). 265:625626.

5. Bjornsson, T. D., M. Dryjski, J. Tluczek, R. Mennie, J. Ronan, T. N. Mellin, and K. A. Thomas. 1991. Acidic fibroblast growth factor promotes vascular repair. Proc. Natl. Acad. Sci. USA. 88:8661-8665.

6. Edelman, E. R., D. A. Adams and M. J. Karnovsky. 1990. Effect of controlled adventitial heparin delivery on smooth muscle cell proliferation following endothelial injury. Proc. Natl. Acad. Sci. USA. 87:3773-3777.

7. McKay, D. J., B. S. Renaux, and G. H. Dixon. 1986. Rainbow trout protamines. Amino acid sequences of six distinct proteins from a single testis. Eur. $J$. Biochem. 158:361-366.

8. Lowary, L. R., F. A. Smith, E. Coyne, and N. W. Dunham. 1971. Comparative neutralization of lung- and mucosal-derived heparin by protamine sulfate using in vitro and in vivo methods. J. Pharm. Sci. 60:638-640.

9. Cundall, R. B., J. B. Lawton, D. Murray, and G. O. Phillips. 1979. Interaction of acidine orange and poly-anions: fluorimetric determination of binding strengths and the influence of simple electrolytes. J. Chem. Soc. Perkin Trans. II:879.

10. Jorpes, E., P. Edman, and T. Thaning. 1939. Neutralization of action of heparin by protamine. Lancet. ii:975-976.

11. Kurtz, A. B., R. S. Gray, S. Markanday, and J. D. Nabarro. 1983. Circulating IgG antibodies to protamine in patients treated with protamine-insulins. Diabetologia. 25:322-324.

12. Stewart, W. J., S. M. McSweeny, M. A. Kellett, D. P. Faxon, and T. J. Ryan. 1984. Increased risk of severe protamine reactions in NPH insulin-dependent diabetics undergoing cardiac catheterization. Circulation. 70:788-792.

13. Clowes, A. W., M. A. Reidy, and M. M. Clowes. 1983. Kinetics of cellular proliferation after arterial injury. I. Smooth muscle growth in the absence of endothelium. Lab. Invest. 49:327-33.

14. Langer, R., L. Brown, and E. Edelman. 1985. Controlled release and magnetically modulated release systems for macromolecules. Drug and enzyme targeting. Methods Enzymol. 112:399-423.

15. Rhine, W. D., S. Sukhatme, D. S. T. Hsieh, and R. Langer. 1980. A new approach to achieve zero-order release kinetics from diffusion-controlled polymer matrix systems. In Controlled Release of Bioactive Materials. R. Baker, editor. Academic Press, New York. 177-187.

16. Duff, G. L., and G. C. McMillan. 1949. The effect of alloxan diabetes on experimental cholesterol atherosclerosis in the rabbit. $I$. The inhibition of experimental cholesterol atherosclerosis in alloxan diabetes. II. The effect of alloxan 
diabetes on the retrogression of experimental cholesterol atherosclerosis. J. Exp. Med. 89:611-630.

17. McGill, H. C., and R. L. Holman. 1949. The influence of alloxan diabetes on cholesterol atheromatosis in the rabbit. Proc. Soc. Exp. Biol. Med. 72:72-75.

18. Duff, G. L., and T. P. B. Payne. 1950. The effect of alloxan diabetes on experimental cholesterol atherosclerosis in the rabbit. III. The mechanism of inhibition of experimental cholesterol atherosclerosis in alloxan-diabetic rabbits. J. Exp. Med. 92:299-311.

19. Cook, D. L., L. M. Mills, and D. M. Green. 1954. The mechanism of alloxan protection in experimental atherosclerosis. J. Exp. Med. 99:119-124.

20. Duff, G. L., D. J. H. Brechin, and W. E. Finkelstein. 1954. The effect of alloxan diabetes on experimental cholesterol atherosclerosis in the rabbit. IV. The effect of insulin therapy of the inhibition of atherosclerosis in the alloxan-diabetic rabbits. J. Exp. Med. 100:371-380.

21. Au, Y. P. T., R. D. Kenagy, and A. W. Clowes. 1990. Heparin selectively inhibits the transcription of tissue-type plasminogen activator in primate arterial smooth muscle cells during mitogenesis. J. Biol. Chem. 267:3438-3444.

22. Wright, T. N., S. Potter-Perigo, and T. Aulinskas. 1989. Proteoglycans and cell proliferation. Am. Rev. Respir. Dis. 140:1132-1135.

23. Snow, A. D., R. P. Bolender, T. N. Wight, and A. W. Clowes. 1990 Heparin modulates the composition of the extracellular matrix domain surrounding arterial smooth muscle cells. Am. J. Pathol. 137:313-330.

24. Bar-Ner, M., M. D. Kramer, V. Schirrmacher, R. Ishai-Michaeli, Z. Fuks, and I. Vlodavsky. 1985. Sequential degradation of heparan sulfate in the subendothelial matrix by highly metastatic lymphoma cells. Int. J. Cancer. 35:483-491.

25. Bar-Ner, M., A. Eldor, L. Wasserman, Y. Matzner, I. R. Cohen, Z. Fuks, and I. Vlodavsky. 1987. Inhibition of heparanase-mediated degradation of extracellular matrix heparan sulfate by non-anti-coagulant heparin species. Blood. 70:551-557.

26. Dauchel, M. C., J. Courty, A. Mereau, and D. Barritault. 1989. Modulation of mitogenic activity and cellular binding of basic fibroblast growth factor by basic proteins. J. Cell Biochem. 39:411-420.

27. Yayon, A., M. Klagsbrun, J. Esko, P. Leder, and D. M. Ornitz. 1991. Cell surface, heparin-like molecules are required for binding of basic fibroblast growth factor to its high affinity receptor. Cell. 64:841-848.

28. Choay, J., M. Petitou, J. C. Lormeau, P. Sinay, B. Casu, and G. Gatti. 1983. Structure-activity relationship in heparin: a synthetic pentasaccharide with high affinity for antithrombin III and eliciting high anti-factor Xa activity. Biochem. Biophys. Res. Commun. 116:492-499.

29. Racanelli, A., J. Fareed, J. M. Walenga, and E. Coyne. 1985. Biochemical and pharmacologic studies on the protamine interactions with heparin, its fractions and fragments. Semin. Thromb. Hemostasis. 11:176-189.

30. Massonnet-Castel, S., E. Pelissier, L. Bara, E. Terrier, B. Abry, P. Guibourt, J. Swanson, B. Joulmes, A. Carpentier, and M. Samama. 1986. Partial reversal of low molecular weight heparin (PK 10169) anti-Xa activity by protamine sulfate. In vitro and in vivo study during cardiac surgery with extracorporeal circulation. Haemostasis. 16:139-146.

31. Nieduszynski, I. 1989. General physical properties of heparin. In Heparin Chemical and Biological Properties, Clinical Applications. D. A. Lane and U. Lindhal, editors. Edward Arnold. Great Britain. 51-63.
32. Guyton, J. R., R. D. Rosenberg, A. W. Clowes, and M. J. Karnovsky. 1980. Inhibition of rat arterial smooth muscle cell proliferation by heparin I. In vivo studies with anticoagulant and non-anticoagulant heparin. Circ. Res. 46:625-634

33. Castellot, J. J., Jr., J. Choay, J.-C. Lormeau, and M. Petitou, E. Sache, and M. J. Karnovsky. 1986. Structural determinants of the capacity of heparin to inhibit the proliferation of vascular smooth muscle cells. II. Evidence for a pentasaccharide sequence that contains a 3-O sulfate group. J. Cell Biol. 102:19791984.

34. Deuel, T. F., R. M. Senior, J. S. Huang, and G. L. Griffin. 1982. Chemotaxis of monocytes and neutrophils to platelet-derived growth factor. J. Clin. Invest. 69:1046-1049.

35. Huang, J. S., S. S. Huang, B. Kennedy, and T. F. Deuel. 1982. Platelet-derived growth factor. Specific binding to target cells. J. Biol. Chem. 257:81308136.

36. Huang, J. S., J. Nishimura, S. S. Huang, and T. F. Deuel. 1984. Protamine inhibits platelet derived growth factor receptor activity but not epidermal growth factor activity. J. Cell. Biochem. 26:205-220.

37. Neufeld, G., and D. Gospodarowicz. 1987. Protamine sulfate inhibits mitogenic activities of the extracellular matrix and fibroblast growth factor, but potentiates that of epidermal growth factor. J. Cell. Physiol. 132:287-294.

38. Taylor, S., and J. Folkman. 1982. Protamine is an inhibitor of angiogenesis. Nature (Lond.). 297:307-312.

39. Andrade, S. P., T.-P. D. Fan, and G. P. Lewis. 1987. Quantitative in-vivo studies on angiogenesis in a rat sponge model. Br. J. Exp. Pathol. 68:755-766.

40. Montalescot, G., E. Lowenstein, M. L. Ogletree, E. M. Greene, D. R Robinson, K. Hartl, and W. M. Zapol. 1990. Thromboxane receptor blockade prevents pulmonary hypertension induced by heparin-protamine reactions in awake sheep. Circulation. 82:1765-1777.

41. Montalescot, G., W. M. Zapol, A. Carvalho, D. R. Robinson, A. Torres and E. Lowenstein. 1990. Neutralization of low molecular weight heparin by polybreen prevents thromboxane release and severe pulmonary hypertension in awake sheep. Circulation. 82:1754-1764.

42. Schapira, M., and B. W. Christman. 1990. Neutralization of heparin by protamine. Circulation. 82:1877-1879.

43. Cook, J. J., S. Niewiarowski, Z. Yan, L. Schaffer, W. Lu, G. J. Stewart, D. M. Mosser, J. A. Myers, and T. E. Malone. 1992. Platelet factor 4 efficiently reverses heparin anticoagulation in the rat without adverse effects of heparinprotamine complexes. Circulation. 85:1102-1109.

44. Weiler, J. M., P. Freiman, M. D. Sharath, W. J. Metzger, J. M. Smith, H. B. Richerson, Z. K. Ballas, P. C. Halverson, D. J. Shulan, S. Matsuo, et al. 1985. Serious adverse reactions to protamine sulfate: are alternatives needed? $J$. Allergy Clin. Immunol. 75:297-303.

45. Holmes, D., R. Vliestra, H. Smith, G. Vetrivec, K. Kent, M. Cowley, D. Faxon, A. Gruentzig, S. Kelsey, K. Detre, M. Van Raden, and M. Mock. 1984. Restenosis after percutaneous transluminal coronary angioplasty (PTCA): A report from the PTCA registry of the National Heart, Lung, and Blood Institute. Am. J. Cardiol. 53:77C-81C.

46. Galan, K., and J. Hollman. 1986. Recurrence of stenoses after coronary angioplasty. Heart \& Lung. 15:585-587. 